\title{
Acute kidney injury after cardiac arrest: the role of coronary angiography and temperature management
}

\author{
Angélique M. E. Spoelstra-de Man *iD and Heleen M. Oudemans-van Straaten
}

Keywords: Cardiac arrest, Acute kidney injury, Coronary angiography, Percutaneous coronary intervention, Hypothermia

Cardiac arrest (CA) leads to acute kidney injury (AKI) in $12-81 \%$ of the patients [1]. Underlying disease, decreased renal perfusion due to shock and use of nephrotoxic medication can all impair renal function. AKI after CA is associated with higher mortality, poor neurological outcome, increased dialysis requirements and prolonged hospital stay $[2,3]$. After CA, coronary angiography with percutaneous coronary intervention (CAG-PCI)) and targeted temperature management (TTM) are applied to improve myocardial function, survival, and neurological outcome. Both interventions have miscellaneous cardiovascular and renal effects and it is unclear whether their net effect on renal function is beneficial or harmful (Fig. 1).

\section{Coronary angiography with percutaneous coronary intervention}

The aim of CAG-PCI after CA is to detect and immediately treat the acute culprit coronary lesions. Potential subsequent improved myocardial perfusion can decrease infarct size, stabilize hemodynamics and reduce the incidence of recurrent cardiac arrest, which can all contribute to better neurological outcome [4]. Faster recovery of cardiac function may also improve renal perfusion. However, the iodinated contrast administered during CAG-PCI may cause tubular damage due to renal vasoconstriction with potential hypoxia and direct cytotoxic effects. Therefore, clinicians are concerned that the potential harm of contrast exposure may prevail over the possible benefit of increased renal perfusion.

* Correspondence: am.spoelstra@amsterdamumc.nl

Department of Intensive Care Medicine, Research VUmc Intensive Care (REVIVE), Amsterdam Cardiovascular Sciences (ACS), Amsterdam Infection and Immunity Institute (AI\&II), Amsterdam University Medical Centers, Location VUmc, De Boelelaan 1117, 1081, HV, Amsterdam, The Netherlands
Current guidelines recommend urgent CAG-PCI for all CA patients presenting with ST-elevation myocardial infarction (STEMI), but there is an ongoing debate whether this procedure in CA patients with non-STEMI should be performed immediately or postponed until the patient has stabilized. Current guidelines recommend immediate CAG-PCI only in selected CA-patients with non-STEMI, i.e., in those with hemodynamic or electrical instability, evidence of ongoing ischemia, or perceived high likelihood of cardiac etiology undergo [5]. Only patients with acute unstable lesions will benefit from immediate CAG-PCI. The reported incidences of acute instable lesions in CA patient with non-STEMI vary from 17 up to 58\%. A meta-analysis in 2017 showed that early CAG-PCI in patients with non-STEMI decreased mortality and improved neurological outcome [6]. However, this meta-analysis mostly included retrospective observational studies and just 1 small RCT (36 patients). In the recent COACT trial immediate CAG-PCI did not improve survival and neurological outcome in 552 post-CA patients with non-STEMI compared to delayed CAG-PCI [7]. However, whereas $64.5 \%$ of the patients had coronary artery disease, only $15 \%$ had acute instable lesions and $5.0 \%$ acute thrombotic occlusions. So, the number of patients who could potentially benefit from immediate CAG-PCI was low. Future trials with more specific inclusion criteria may identify subgroups of CA-patients with non-STEMI with a higher probability of acute instable lesions who could potentially benefit from urgent CAG-PCI.

Recent studies show that early CAG-PCI does not increase the risk of AKI. In the COACT trial, the incidence of AKI and need for renal-replacement therapy did not differ between early vs. late CAG-PCI [7]. In the post hoc analysis of the targeted temperature management 


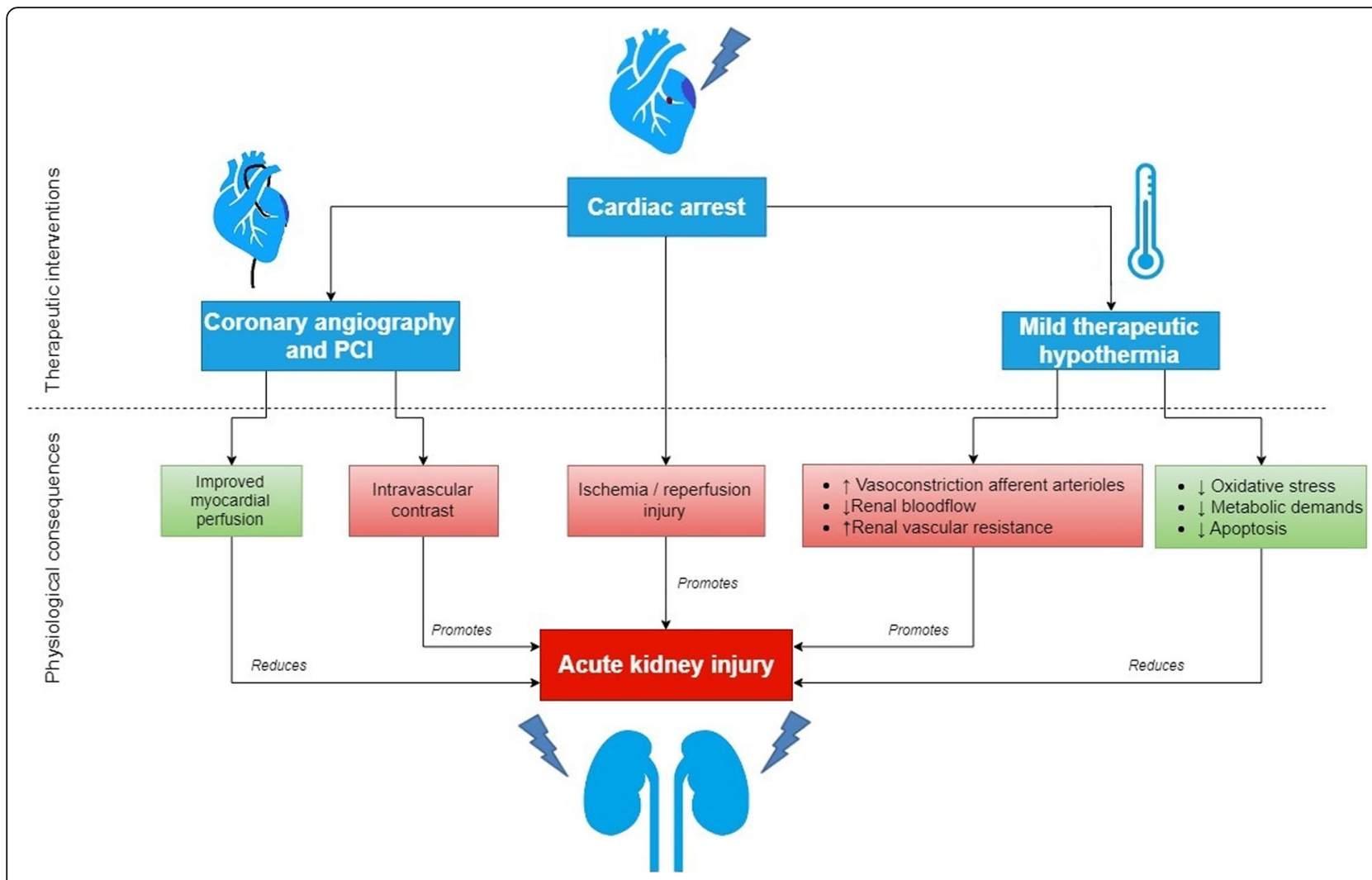

Fig. 1 The physiological consequences of therapeutic interventions post-cardiac arrest on acute kidney injury

(TTM) trial, early CAG-PCI was even associated with less AKI [1]. Forty-two percent of the CA patients undergoing early CAG-PCI developed AKI, compared to $50 \%$ of the patients with late/no CA-PCI $(p=0.014)$ with worse severity of AKI in the late/no CAG-PCI group $(p=0.007)$. However, groups were not randomized for early CAG-PCI and in adjusted analyses timing of CAG-PCI was not an independent risk factor. Furthermore, a cohort study of 199 CA patients showed that exposure to iodinated contrast from CAG or CT scan was not associated with AKI. In addition, intra-arterial contrast did not increase the risk of AKI [8]. The aforementioned meta-analysis unfortunately did not report renal function [6]. Altogether, immediate CAG-PCI after CA appears to be safe and should not be postponed because of concern of contrast-induced nephrotoxicity when indicated.

\section{Targeted temperature management}

After CA, TTM is frequently applied for neurological protection and to preserve the function of vital organs, including the kidney. Animal studies suggest that hypothermia reduces renal metabolic demand and oxygen consumption and can limit renal ischemia/reperfusion injury by suppression of oxidative stress and reduction of apoptosis. However, TTM has circulatory consequences. Hypothermia induces peripheral vasoconstriction creating a temporary relative central hypervolemia with increased renal blood flow and increased diuresis mediated by suppression of vasopressin [9]. Subsequent low circulating volume and high afterload may cause hypotension and a decrease in renal blood flow with vasoconstriction of the afferent arterioles, potentially creating a vicious circle of ongoing decrease in renal blood flow and increase of renal vascular resistance. The renal function, already impaired due to CA, can become progressively depressed.

A meta-analysis of 19 clinical studies in different populations did not find any effect of mild therapeutic hypothermia (MTH) on prevention of AKI. However, most studies were not primarily designed to investigate the effect of MTH on renal function and the definition of AKI varied substantially [10]. Only locally applied hypothermia by selective renal artery perfusion appeared to be protective for renal function in one very small $(n=30)$ RCT in patients undergoing thoracoabdominal aortic aneurysm repair compared to normothermic perfusion. Meta-regression analysis found that a lower target cooling temperature was associated with a decreased risk of AKI [11]. However, this association was predominantly due to the aforementioned study with intra-renal arterial cooling of $15^{\circ} \mathrm{C}$. [11] After removal of this study, this association did not persist. 
Studies specifically addressing the effect of systemic therapeutic hypothermia on renal function in CA patients are scarce. In an explorative analysis of participants of the hypothermia after cardiac arrest trial, MTH was associated with delayed improvement in renal function, but after 4 weeks the difference with normothermic patients had disappeared [12].

Recently, a post hoc analysis of the TTM trial, which previously found no survival or neurological benefit of cooling to $33^{\circ} \mathrm{C}$ compared to $36^{\circ} \mathrm{C}[1]$, showed that patients in the $33^{\circ} \mathrm{C}$ group needed more intravenous fluids and vasopressors, and had more AKI with worse severity compared to those maintained at $36{ }^{\circ} \mathrm{C}$, but in adjusted analysis the difference was not significant.

In conclusion, with regard to renal function, CAG-PCI can be performed safely when indicated in CA-patients, even immediately after the return of spontaneous circulation. Mild therapeutic hypothermia is not renoprotective.

\section{Abbreviations}

AKI: Acute kidney injury; CA: Cardiac arrest; CAG-PCl: Coronary angiography with percutaneous coronary intervention; MTH: Mild therapeutic hypothermia; STEMI: ST-elevation myocardial infarction; TTM: Targeted temperature management

\section{Acknowledgements}

We would like to thank H.J. de Vries for composing Fig. 1 for our manuscript.

Funding

The authors received no specific funding for this work.

Availability of data and materials

Not applicable.

\section{Authors' contributions}

$\mathrm{AS}$ and $\mathrm{HO}$ both wrote the manuscript and approved the final version of the manuscript

Ethics approval and consent to participate

Not applicable.

\section{Consent for publication}

Not applicable.

\section{Competing interests}

The authors declare that they have no competing interests.

\section{Publisher's Note}

Springer Nature remains neutral with regard to jurisdictional claims in published maps and institutional affiliations.

Received: 25 April 2019 Accepted: 13 May 2019

Published online: 30 May 2019

\section{References}

1. Rundgren M, Ullen S, Morgan MPG, Glover G, Cranshaw J, Al-Subaie N, Walden A, Joannidis M, Ostermann M, Dankiewicz J, Nielsen N, Wise MP. Renal function after out-of-hospital cardiac arrest; the influence of temperature management and coronary angiography, a post-hoc study of the target temperature management trial. Crit Care. 2019;23(1):163.

2. De Rosa S, Antonelli M, Ronco C. Hypothermia and kidney: a focus on ischaemia-reperfusion injury. Nephrol Dial Transplant. 2017;32(2):241-7.

3. Storm C, Krannich A, Schachtner T, Engels M, Schindler R, Kahl A, et al. Impact of acute kidney injury on neurological outcome and long-term survival after cardiac arrest - a 10year observational follow up. J Crit Care. 2018;47:254-9.

4. Noc M, Fajadet J, Lassen JF, Kala P, MacCarthy P, Olivecrona GK, et al. Invasive coronary treatment strategies for out-of-hospital cardiac arrest: a consensus statement from the European association for percutaneous cardiovascular interventions (EAPCI)/stent for life (SFL) groups. Eurolntervention. 2014;10(1):31-7.

5. Callaway CW, Donnino MW, Fink EL, Geocadin RG, Golan E, Kern KB, et al. Part 8: post-cardiac arrest care: 2015 American Heart Association guidelines update for cardiopulmonary resuscitation and emergency cardiovascular care. Circulation. 2015;132(18 Suppl 2):S465-82.

6. Khan MS, Shah SMM, Mubashir A, Khan AR, Fatima K, Schenone AL, et al. Early coronary angiography in patients resuscitated from out of hospital cardiac arrest without ST-segment elevation: a systematic review and metaanalysis. Resuscitation. 2017;121:127-34.

7. Lemkes JS, Janssens GN, van der Hoeven NW, Jewbali LSD, Dubois EA, Meuwissen $\mathrm{M}$, et al. Coronary angiography after cardiac arrest without STsegment elevation. N Engl J Med. 2019;380(15):1397-07.

8. Petek BJ, Bravo PE, Kim F, de Boer IH, Kudenchuk PJ, Shuman WP, et al. Incidence and risk factors for postcontrast acute kidney injury in survivors of sudden cardiac arrest. Ann Emerg Med. 2016;67(4):469-76 e1.

9. Morgan ML, Anderson RJ, Ellis MA, Berl T. Mechanism of cold diuresis in the rat. Am J Phys. 1983;244(2):F210-6.

10. Susantitaphong P, Alfayez M, Cohen-Bucay A, Balk EM, Jaber BL. Therapeutic hypothermia and prevention of acute kidney injury: a meta-analysis of randomized controlled trials. Resuscitation. 2012;83(2):159-67.

11. Koksoy C, LeMaire SA, Curling PE, Raskin SA, Schmittling ZC, Conklin $L D$, et al. Renal perfusion during thoracoabdominal aortic operations: cold crystalloid is superior to normothermic blood. Ann Thorac Surg. 2002;73(3):730-8.

12. Zeiner A, Sunder-Plassmann G, Sterz F, Holzer M, Losert H, Laggner AN, et al. The effect of mild therapeutic hypothermia on renal function after cardiopulmonary resuscitation in men. Resuscitation. 2004;60(3):253-61. 